\title{
Yoğun Bakım Hastalarında Spiritüel Değerlendirme
}

\author{
Spiritual Assessment in Intensive Care Patients
}

\section{Zübeyde Kaçal', Nilüfer Demirsoy²}

Sakarya Üniversitesi Tıp Fakültesi, Sakarya

Osmangazi Üniversitesi Tıp Fakültesi Tıp Tarihi ve Etik A.D., Eskişehir

Yazıșma Adresi / Correspondence:

\section{Zübeyde Kaçal}

Sakarya Üniversitesi Tıp Fakültesi, Korucuk/ Sakarya

\author{
T: +90 $5307717286 \quad$ E-mail: zkacal@sakarya.edu.tr
}

Geliş Tarihi / Received : 16.01.2018 Kabul Tarihi / Accepted : 19.03.2018

\begin{abstract}
Öz
Sağıkta bütüncül yaklaşım bireyin fiziksel, zihinsel, ruhsal, sosyal ve manevi açıdan bir bütün olarak değerlendirilme esasına dayanır. Bireyin sağlığını koruyabilmesi için fiziksel, ruhsal, sosyal ve manevi açıdan sağıı̆ının değerlendirilmesi gerekmektedir. Spiritualite; bireyin kendisi ve diğer insanlarla ilișkisini, evrendeki yerini, yașamın anlamını anlama ve kabul etme çabasıdır. Aynı zamanda yaşam boyu kazanılan bilgilerin bir sonucudur. Spiritualite yaşamın amacını oluşturan ve bireye anlamlı gelen unsurları içerir. Spirituel boyut sağıkla ilişkili dinamikler, tutum ve davranışlar üzerinde güçlü etkisi bulunmasından dolayı holistik bakım felsefesinin "temel unsuru” olarak görülmektedir. Spiritüel bakım; bireyin duygusal ihtiyaçları basta olmak üzere, fiziksel ve ruhsal olarak yașadığı sıkıntılarla baș etmesinde inançların, (her zaman tanıı ile ilişkilendirilmeyen) bireysel öğrenme ve kendini gerçekleştirme yaklaşımlarının tedavi sürecine dahil edilmesidir. Yoğun bakım üniteleri fiziksel durumu ağır olan hastaların monitör ile izlenerek yaşam fonksiyonlarının desteklendiği, özel tedavi yöntemlerinin uygulandığı, karmaşık cihazların bulunduğu ve önemli ölçüde dikkat gerektiren bölümlerdir.

Yoğun bakım ünitesine yatırılma hasta kadar aile üyelerinin de yaşam biçimlerini olumsuz yönde etkilemektedir. Sağlık profesyonelleri, tedavi ve bakım için birey hakkında veri toplarken bütüncül bakış açııını benimsemeli, kolay gözlemlenen fiziksel sorunlarla birlikte sosyal, psikolojik ve spiritüel gereksinimler konusunda da bilgi almalıdır. ( Sakarya Tıp Dergisi 2018, 8(2):170-175 )

Anahtar Yoğun Bakım; Spiritualite; Spiritüel bakım

Kelimeler
\end{abstract}

\section{Abstract}

The holistic approach to health is based on the principle of the individual being evaluated as a whole in terms of physical, mental, spiritual, social and spiritual. In order to protect the health of the individual, physical, mental, social and spiritual health needs to be assessed. Spirituality; it is the effort of the individual to understand and accept the relationship with himself and other people, his place in the world, the meaning of life. At the same time, it is a result of the information that has been acquired for life. Spirituality contains the elements that make up the purpose of life and are meaningful to the individual. The spiritual dimension is seen as a "fundamental element" of the holistic care philosophy because of its strong influence on health-related dynamics, attitudes and behaviors. Spiritual care; beliefs, individual learning and self-realization approaches (which are not always associated with God) are included in the treatment process when the individual copes with physical and mental stresses, especially emotional needs. Intensive care units are those in which patients with severe physical conditions are monitored with monitors to support their life function, special treatment methods are applied, complex devices are present, and significant attention is required.

Admission to intensive care unit affects the life style of the family members as well as the patients in the negative direction. Health professionals should adopt a holistic perspective when collecting data about the individual for treatment and care, and should also be familiar with social, psychological, and spiritual requirements as well as easily observed physical problems. ( Sakarya Med J, 2018, 8(2):170-175 ). 
Sakarya Tip Dergisi

2018;8(2):170-175

KAÇAL ve Ark.

Yoğun Bakım Hastalarında Spiritüel Değerlendirme

\section{Giriş}

Dünya Sağlık Örgütü (WHO) sağlığı; "Yalnızca hastalık veya sakatlığın olmayışı değil, fiziksel, sosyal ve ruhsal yönden tam bir iyilik halidir" şeklinde tanımlamıştır. Bu durumda bireyin iyilik halinin sürdürebilmesi için fiziksel, ruhsal, sosyal ve manevi (spirituel) sağlığının da değerlendirilmesi gereklidir. ${ }^{1}$

\section{Spiritualite}

Bireyin bütüncül sağlğ̆; spiritualite dahil bütün bakım türlerinin hayata geçirilmesi ile mümkündür. ${ }^{2,3}$ Spiritualite kelimesi günümüze kadar çok farklı anlamlarda kullanılmıştır. 12. yy da insan yaşamının bedensel yönünün tersine psikolojik yönünü adlandırmak için kullanılırken, 15. ve 16. yy da din görevlilerini göstermek için kullanılmıştır. Modern anlamda ilk kez 17 yy da kullanılmıştır. 20. yy da tatmin edici bir tanımı bulunmamakla birlikte birçok dilde dini ve dini olmayan anlamlarda yaygın olarak kullanıldığı bildirilmektedir. Spiritualite kavramına ilgi 1960'larda özellikle ikinci dünya savaşı sonrasında artmıştır. Spiritualite kavramına ilginin artmasının nedenleri olarak; maddi şeylerin mutluluk getirmemesi, modern bilimin ölüm, acı çekme ve kayıp karşısında insanların yaşadığı kişisel anlam kaybını göstermede yetersiz kalması, ağrı gibi birçok problemin bilimsel yaklaşım ile çözülememesi, şiddet gibi sosyal ve kültürel problemlerin artışına cevap bulma isteği, huzurlu, anlamlı yaşam ve ilişki arayışı gösterilmektedir. ${ }^{4}$ Spiritüelite ile ilgili çeşitli tanımlar bulunmaktadır. Spiritualite; bireyin kendisi ve diğer insanlarla ilişkisini, evrendeki yerini, yaşamın anlamını anlama ve kabul etme çabasıdır. Aynı zamanda yaşam boyu kazanılan bilgilerin bir sonucudur. Spiritualite yaşamın amacını oluşturan ve bireye anlamlı gelen unsurları içerir. Spiritüalite; zorluklara karşı sağlam duruş sergilemede önemli katkısı olan bir baş etme sürecidir. ${ }^{5}$ Beden ve ruhu etkileyen ve aynı zamanda beden ve ruhtan etkilenen "birleştirici güç" olarak da tanımlanabilir. Spiritüalite dinin ilk komponenti sayılabilir ancak dini inanç ve uygulamalarla sınırlandırılamayacak kadar geniş bir kavramdır. Spiritüel değerlerin bireyin kendisini iyi hissetmesinin temelini oluşturduğu da unutulmamalıdır. ${ }^{6}$

\section{Spirituel Bakım}

Spirituel boyut; sağlıkla ilişkili dinamikler, tutum ve davranışlar üzerinde güçlü etkisi bulunmasından dolayı holistik bakım felsefesinin temel unsuru olarak görülmektedir. Spiritüel bakım; bireyin duygusal ihtiyaçları başta olmak üzere, fiziksel ve ruhsal olarak yaşadığı sıkıntılarla baş etmesinde inançların, (her zaman tanıı ile ilişkilendirilmeyen) bireysel öğrenme ve kendini gerçekleştirme yaklaşımları ile birlikte tedavi sürecine dahil edilmesidir. Dünya Tabipler Birliği Lizbon Bildirgesi'nde (1981) "Hasta uygun bir dini temsilcinin yardımı da dahil olmak üzere ruhi ve manevi teselliyi kabul veya reddetme hakkına sahiptir" ifadesi yer almaktadır. Dünya Tabipler Amsterdam Bildirgesi'nde (1994) ise "Herkesin, kendi ahlaki ve kültürel değerlerine, dinsel ve felsefi inançlarına sahip olma ve bunlara saygı gösterilmesini isteme hakkı vardır" , "Hastaların, bakım ve tedavileri süresince her zaman manevi destek ve yol gösterime hakları vardır." ifadesi yer almaktadır. Hasta Haklarına iliş̧kin Avrupa Statüsü (Ana Sözleşmesi) Temel Dökümanı (2002) 12. Maddesinde "Her birey kendi kişisel ihtiyaçlarına göre teşhis ve tedavi programlarını yönlendirme hakkına sahiptir." ifadesinde manevi bakıma vurgu yapılmaktadır. ${ }^{2}$ Hasta hakları yönetmeliğinin 38. Maddesinde "Sağlık kurum ve kuruluşlarının imkanları ölçüsünde hastalara dini vecibelerini serbestçe yerine getirebilmeleri için gereken tedbirler alını." ifadesi yer almaktadır. ${ }^{7}$ 


\section{Yoğun Bakım Ve Spiritüel Bakım}

\section{Yoğun Bakım Ünitesi}

Yoğun bakım üniteleri; fiziksel durumu ağır olan hastaların monitör ile izlenerek yaşam fonksiyonlarının desteklendiği, özel tedavi yöntemlerinin uygulandığı, karmaşık cihazların bulunduğu önemli ölçüde dikkat gerektiren bölümlerdir. ${ }^{8}$ Bu ünitelerde kalan hastaların burada kaldıkları süre içinde olumsuz emosyonel sonuçlara maruz kaldıkları belirtilmektedir. ${ }^{9}$ Hastaların yaşadığı ölüm korkusu, beden bütünlüğünün bozulması, gelecek kaygısı, yakınlarından ve alıştığı çevreden ayrılma, ağrı ve invaziv girişimler, Yaşamın tehdit altında olması, alışık olunmayan çevre ve kişiler, hareket kısıtılığı, yatağa bağımlı olma, uyku düzeninin bozulması, aile bireyleri ve yakılarını görememe, araçlara veya yoğun bakım ünitesine bağımlılık duygusu, sık tekrarlanan ağrılı manipülasyonlar, hastalık, tedavi ve uygulamalar hakkında yeterince bilgilendirilmeme hastaları olumsuz etkileyen sebepler arasında gösterilmektedir..$^{9,10}$

Yoğun bakım ünitesine yatırılma hasta kadar aile üyelerinin de yaşam biçimlerini olumsuz yönde etkilemektedir. Verilecek olan bakım hem hasta hem de hasta yakınlarını kapsayacak şekilde olmaIıdır. ${ }^{1}$

\section{Yoğun Bakım Hastalarının Spiritüel Bakım Gereksinimlerinin Değerlendirilmesi}

- Spiritüel değerlendirmede hastanın Tanrı, üstün güç, dua etme, dini mekanlar ( kilise, cami) dini liderler hakkındaki ifadelerine dikkat edilmeli,

- Hastanın kendi üzerinde ve odasındaki spiritüel yönelimlere ilişkin simgeler değerlendirilmeli, (kitaplar ve sembollerin bulunması)

- Hasta spiritüel distres belirtileri açısından değerlendirilmeli, (Cesaret, anksiyete, her zamanki spiritüel uygulamalara katılmakta güçsüzlük, yetersizlik, ağlama, suçluluk ifadesi, uyku bozuklukları, spiritüel güvenin bozulması, tanrı ya da büyük güçten uzaklaşma hissi, sağlık personeline, aileye, tanrı ya da büyük güç'e karşı öfke, inanç ve değer sistemlerini reddetme, yaşamdaki anlam ve amacı kaybetme $)^{2}$

- S Sağlık profesyoneli bakım verdiği bireyin "Neden ben?, Bunu hak etmek ve bunu yaşamak için ne yaptım?, Tanrı beni cezalandırıyor mu?, Öldükten sonra bana ne olacak? ,Yokluğum fark edilecek mi?, Özlenecek miyim?, Hatırlanacak mıyım?” gibi spiritüel gereksinimini yansıtan sözlerin farkında olmalı,

- Empati kurarak şefkat göstermeli ve varlığının farkına varılmasına yardım edilmeli,

- Hastalar fiziksel, duygusal ve manevi yönden bir bütün olarak değerlendirilmeli,

- Hastaların manevi öyküleri öğrenilmeli,

- Manevi endişelerin, kaygıların belirtileri değerlendirilmeli,

- Hastaların korkuları, umutları, acıları ve hayalleri dinlenmeli, sözleri önyargısız olarak kabul edilmeli,

- Hastanın inançları ve hastalığın anlamını etkileyen değerleri hakkında veri toplanmalı,

- Hastalara manevi desteklere yönelik kaynak sağlanmalı,

- Hastaların ait olduğu dine yönelik uygulamalarını yerine getirmesine yardımcı olunmalı,

- Hasta için manevi önem taşıyan eşyalara sayg gösterilmeli,

- Gerektiğinde din görevlileri gibi diğer profesyoneller ile iletişim kurulmalı,

- Hastanın elini tutmak, onu dinlemek, dua etmesine olanak sağlamak, masaj, dokunma, müzik, meditasyon gibi aktivitelerin yapılması sağlanmalı,

- Kişinin manevi inanç ve alışkanlıkları kabul edilmeli,
Sakarya Tip Dergis 2018;8(2):170-175

KAÇAL ve Ark. Yoğun Bakım Hastalarında Spiritüel Degerlendirme 
- Bu duruma neden olan etkenler değerlendirilmeli,

- Önyargisız bir tutum sergilenmeli,

- Manevi gereksinimlerin karşılanmasında yardımcı olunmalı,

- Geçmişteki inançları, alışkanlıkları hakkında sorular sorarak kişinin duygularını ifade etmesi sağlanmalı, ${ }^{11}$

- Hastayla iletişime geçilmelidir. (Yoğun bakım hastalarının bilinci organik bir bozukluk sonucu ya da sedasyon verilmesiyle kapanır. İsiitme duyusu en son kaybedilen duyudur. Bilinci kapalı hastaların işitme duyusu devam eder. Hastanın sözel iletişimin kaybolması ya da azalması duyusal uyaran azalmasına ve buna bağlı olarak da; korku, kaygı, depresyon, halüsinasyon ve deliryum gibi psikolojik reaksiyonlar görülmesine sebep olabilir. Yapılan çalışmalarda; hastalar bilinçleri kapalı iken gerçekleşen çeşitli konuşmaları duyduklarını ifade etmişlerdir.) 3,4,12,13

\section{Spiritüel Değerlendirmede Karşılaşılan Engeller}

- Spiritüal konu ile ilgili bilgi eksikliği,

- Farklı kültürlerin içinde dini ifadelerin çeşitliliğinden kaynaklı bilgi ve tecrübe eksikliği,

- Zaman kısıtlilığı,

- Spiritüel bakımın öneminin sağlık profesyonelleri tarafından yeterince bilinmemesi,

- Spiritüel gereksinimleri belirlemeye ve karşılamaya ilişkin planlamanın etkin olarak yapılamaması,

- Sağlık profesyonellerinin hastalara kendi görüşlerini empoze etmek istememeleri,

- Etik ve mesleki sınırları ihlal etmemek içinde temkinli yaklaşma zorunluluğu karşışşılan engellerdendir. ${ }^{2,12}$

Ayrıca yoğun bakım hastalarının durumunun hayati olması, aciliyet gerektirmesi ve bilinç düzeyindeki değişiklikler nedeniyle fizyolojik bakımı daha öncelikli olurken, psikolojik bakımı ihmal edilmektedir. ${ }^{9}$

\section{Yoğun Bakım Hastalarında Spiritüel Bakım}

Yoğun bakım ünitesine yatırılma hem hastanın hem de hasta yakınlarının yaşam biçimlerini olumsuz yönde etkilemektedir. Verilecek olan bakım hasta ve hasta yakınlarını kapsayacak şekilde olmaIıdır. Spiritüel bakımda empati kurmak, hasta ile iletişime geçmek, hastaya güven vermek, destek olmak, çevre düzenlemeleri yapmak, terapötik dokunuşlar, masaj, müzik terapi ve aileye yönelik uygulamalar oldukça önemlidir. Hasta için değerli olan eşyalar hasta odasına konulabilir. (Resimler, fotoğraflar) Hastaya her gün fiziksel bakım yapılmalı ve hasta yakınları bakıma dahil edilmelidir. Hasta ve yakınları arasında temas sağlanmalıdır. Hastanın vücuduna özel yağlar ya da kremlerle terapötik uygulamalar yapılabilir. Ayrıca hastanın aktif olarak dinlenmesi ve ona güven verilmesi oldukça önemlidir. ${ }^{14}$

\section{Sonuç}

Çeşitli çalışmalarda; spiritüel bakımın fiziksel ve ruhsal sağlığı güçlendirdiği, stres ve kan basıncını azalttığı, uykuyu iyileştirdiği, kronik ağrıyı azalttığı, ilişkilerdeki tepkiselliği azalttı̆̆ı, depresyon ve madde kullanımını azalttığı saptanmıştır. Bu nedenle sağık profesyonelleri tedavi ve bakım için birey hakkında veri toplarken bütüncül bakımı benimsemeli, fiziksel sorunlarla birlikte sosyal, psikolojik ve spiritüel gereksinimler konusunda da bilgi almalıdılar. Sağlık profesyonelleri spiritüalite, spiritüel gereksinimler, spiritüel distres ile baş etme ve bireylerin spiritüel gereksinimlerinin karşı- 
lanmasına odaklanan bir yaklaşım içerisinde olmaları hastalar için yararlı olacaktır. Bu yaklaşımın geliştirilebilmesi için hasta ya da sağlıklı bireylerle çalışan sağlık profesyonellerinin öğrenim süreçlerinde sağık, hastalık, ölüm, psikososyal özellikler, spiritüel psikoloji gibi konulara yer verilmesi ve sağlık profesyonellerinin spiritüaliteye yönelik kendi inançlarının, değerlerinin ve tutumlarının farkında olmaları ve bu farkındalıkla sağlıkı birey, hastanın manevi gereksinimlerini karşılamaya yönelik bakım vermeleri gerekmektedir. ${ }^{5}$ Sağılı profesyonellerinin spiritüel bakıma ilişkin bilgi düzeylerinin belirlenmesi için çalışmaların yapılması ve sonuçlar doğrultusunda hizmet içi eğitim programları planlanması önerilmektedir. ${ }^{15,16}$

Eğitim programları içerisine; özel durumu olan hasta ve yakınlarına yaklaşım, hasta ve ailelerine psikolojik bakım, hasta ve hasta yakını ile iletişim, YB (yoğun bakım) ortamına adaptasyon ve bakım konularının eklenmesi önerilmektedir. ${ }^{3}$

Temel amacımız yoğun bakımda hastanın rahatını sağlamak, anksiyetesini azaltmak ve tedaviye uyumunu kolaylaştıııı girişimlerde bulunmaktır. Bu girişimler sırasında hasta ve yakınlarının yaşadıkları spiritüel distres ile baş etmesine destek olmak ve spiritüel gereksinimleri dikkate almak gerekmektedir. Hastaların spiritüel boyutunun farkında olunması destekleyici spiritüel bakımın verilmesinde önemlidir. ${ }^{15}$

Yoğun bakım ünitelerinde hasta ile göz teması kurulması, dokunma ve beden dilinin tercih edilmesi, sürekli iletişim halinde olunması, her uygulama öncesi açıklama yapılması gibi girişimler ile bireyin $\mathrm{YB}$ ünitesine uyumu, anksiyete ile etkin baş etme teknikleri geliştirebilmesi ve iletişimin sürekliliğinin sağlanması açısından önemlidir. ${ }^{17}$
Sakarya Tip Dergisi 2018;8(2):170-175

KAÇAL ve Ark.

Yoğun Bakim Hastalarinda

Spiritüel Degerlendirme 
1. Uğurlu SE, Başbakkal Z. Yoğun bakımda yatan çocuk hastaların annelerinin manevi bakım gereksinimleri. Türk yoğun bakım derneği dergis 2013; 11: 17-24

2. Demirsoy N. Holistic Care Philosophy for Patient-Centered Approac hes and Spirituality. Patıent Centered Medıcıne 119

3. Aktaş Y. Yoğun Bakım Hemşirelerinin Hastaların psikolojik bakım ge reksinimlerini belirlemeye ve uygulamaya yönelik görüşlerinin incelenmesi. Yüksek Lisans Tezi İzmir Katip Çelebi Üniversitesi Sağlık Bilimleri Enstitüsü Hemșirelik Anabilim Dalı 2016

Sakarya Tip Dergis

2018;8(2):170-175

KAÇAL ve Ark

Yoğun Bakım Hastalarnd

Spiritüel Değerlendirme
4. Yılmaz M. Holistik Bakımın Bir Boyutu: Spiritualite, Doğası ve Hemşirelik ilişkisi. Anadolu hemşirelik ve Sağlık Dergisi 2011; 14 (2): 61-70

5. Öz F, Hiçdurmaz D. Stresle Bașetmenin Bir Boyutu Olarak Spiritüalite. Anadolu hemşirelik ve Sağlık Dergisi 2013; 16 (1): 50-54

6. Arslan H, Şener DK. Stigma, Spiritüalite ve Konfor Kavramlarının Geliştirme Sürecine Göre İrdelenmesi. Maltepe Üniversitesi Hemşirelik Bilim ve Sanatı Dergisi 2009; 2: 1-8

7. Hasta Hakları Yönetmeliği Resmi Gazete Tarihi: 01.08.1998 Resmi Ga zete SayıIs: 23420

8. Uzelli D, Karhan EA. Yoğun Bakım Hastalarında Duyusal Girdi Sorunları ve Hemşirelik Yaklaşımı. Florence Nightingale Hemşirelik Dergisi 2014 22 (2): $120-128$

9. Hintistan S, Nural N, Öztürk H. Yoğun bakım ünitesinde yatan hasta deneyimleri. Yoğun bakım hemşireliği dergisi 2009; 13 (1): 40-46
10.Sahin G, Buzlu S. Yoğun Bakım Ünitelerinde Anksiyeteye yönelik hemșirelik bakımı. Yoğun bakım hemșireliği dergisi 2016; 20 (1): 65-69

11. http://kadinvehastaliklari.com/spirituel-distres-manevi-sikinti-vehemsirelik-bakimi/ Erişim tarihi: 31.10.2017 13:00

12. Çınar F, Arslan FE. Spiritüalizm ve Hemșirelik: Yoğun Bakım Hastalarında Spiritüel Bakımın Önemi. G. O.P. Taksim E. A. H JAREN 2017, 3 (1): $37-42$

13. Daştan NB, Buzlu S. Meme Kanseri Hastalarında Maneviyatın Etkileri ve Manevi Bakım. Maltepe Üniversitesi Hemşirelik Bilim ve Sanatı Dergisi 2010; 3 (1): 1 - 6

14.http://kanser.gov.tr/Dosya/Sunular/terminalHanife2015.pdf Erişim tarihi: 15.12 .2017 saat: 12.30

15. Eğlence R, Şimşek N. Hemşirelerin Maneviyat ve Manevi Bakım Hakkındaki Bilgilerinin Değerlendirilmesi. Acıbadem Üniversitesi Sağık Bilimleri Dergisi 2014; 5 (1): 48-53

16. Boztilki M, Ardıc E. Maneviyat ve Sağılı. G.O.P. Taksim E.A.H. JAREN 2017; 3 (Ek sayı): 39-45

17. Kumsar AK, Yılmaz FT, Yoğun bakım ünitesinin yoğun bakım hastas üzerindeki Etkileri ve Hemşirelik Bakımı. Hemşirelik Eğitim ve Araştırma Dergisi 2013; 10 (2): 56-60 